\title{
Article
}

\section{Prognostic Role of Anemia in COVID-19 Patients: A Meta-Analysis}

\author{
Marco Zuin ${ }^{1, * \mathbb{D}}$, Gianluca Rigatelli ${ }^{2}$, Laura Quadretti ${ }^{3}$, Luisella Fogato ${ }^{4}$, Giovanni Zuliani ${ }^{1}$ and Loris Roncon ${ }^{2}$ \\ 1 Department of Translational Medicine, Section of Internal and Cardio Respiratory Medicine, \\ University of Ferrara, 44124 Ferrara, Italy; giovanni.zuliani@unife.it \\ 2 Department of Cardiology, Rovigo General Hospital, 45100 Rovigo, Italy; jackyheart@libero.it (G.R.); \\ roncon.loris@gmail.com (L.R.) \\ 3 Department of Medicine, Casa di Cura Porto Viro, 45014 Rovigo, Italy; quadrettilaura@gmail.com \\ 4 Department of General Surgery, Santa Maria degli Angeli Hospital, 06081 Adria, Italy; \\ fogato.luisella@gmail.com \\ * Correspondence: marco.zuin@edu.unife.it
}

Citation: Zuin, M.; Rigatelli, G.; Quadretti, L.; Fogato, L.; Zuliani, G.; Roncon, L. Prognostic Role of Anemia in COVID-19 Patients: A MetaAnalysis. Infect. Dis. Rep. 2021, 13, 930-937. https://doi.org/10.3390/ idr13040085

Academic Editor: Nicola Petrosillo

Received: 15 September 2021

Accepted: 28 October 2021

Published: 31 October 2021

Publisher's Note: MDPI stays neutral with regard to jurisdictional claims in published maps and institutional affiliations.

Copyright: (C) 2021 by the authors. Licensee MDPI, Basel, Switzerland. This article is an open access article distributed under the terms and conditions of the Creative Commons Attribution (CC BY) license (https:/ / creativecommons.org/licenses/by/ $4.0 /)$.

\begin{abstract}
Introduction. The prevalence and prognostic implications of anemia in patients infected by the SARS-CoV-2 remains unclear. We performed a systematic review and meta-analysis to assess the prevalence and mortality risk in COVID-19 patients with anemia. Methods. Preferred Reporting Items for Systematic Reviews and Meta-Analyses guidelines were followed in abstracting data and assessing validity. We searched MEDLINE and Scopus to locate all the articles published up to 1 September 2021, reporting data on the adjusted OR (aOR) for mortality among COVID-19 patients with anemia. The pooled prevalence of anemia among COVID-19 patients was calculated using a random effects model and presenting the related $95 \%$ confidence interval (CI), while the mortality risk was estimated using the Mantel-Haenszel random effects models with odds ratio (aOR) and related 95\% CI. Statistical heterogeneity was measured using the Higgins $\mathrm{I}^{2}$ statistic. Results. Five studies, enrolling 9.623 COVID-19 patients [3.707 males (38.5\%)], met the inclusion criteria and were included in the final analysis. The pooled prevalence of anemia was $25.6 \%$ of cases (95\% CI: 8.3-56.5\%), with high heterogeneity $\left(\mathrm{I}^{2}=98.9 \%\right)$. Meta-regression showed that the anemia prevalence was influenced by a direct correlation with age $(p=0.007)$ and chronic kidney disease $(p=0.004)$ as moderating variables. Conversely, an inverse relationship was observed with male gender $(p<0.0001)$. Anemia was significantly associated with higher risk of short-term mortality (aOR: $1.69,95 \%$ CI: $1.28-2.24, p<0.001)$, with low heterogeneity $\left(\mathrm{I}^{2}=0 \%\right)$. Conclusions. Anemia represents a major comorbidity in about 25\% of COVID-19 patients and it is associated with about $70 \%$ higher risk of short-term mortality.
\end{abstract}

Keywords: anemia; COVID-19; prevalence; mortality

\section{Introduction}

Over the last two years, several analyses have demonstrated that the prognosis of patients with COVID-19 infection is closely related to the burden of associated comorbidities, such as arterial hypertension (HT), atrial arrhythmias, diabetes mellitus (DM) and more generally to cardiovascular disease (CVDs) [1-5]. However, few investigations, often achieving conflicting results, have focused their attention on the association between anemia in COVID-19 patients and the related risk of short-term mortality [6,7]. Conversely, recent studies have demonstrated that pre-existing anemia represents a risk factor for severe COVID-19 infection [8,9]. As known, anemia remains a global health concern, representing a significant risk factor for hospitalization and/or mortality, especially in those patients infected by the SARS-CoV-2 virus who present other comorbidities associated with a poor prognosis [10-12]. Indeed, anemia can further reduce oxygen delivery to peripheral tissue in COVID-19 patients who have an increased oxygen demand due the interstitial pneumonia. Therefore, in the present study we estimated the pooled prevalence and the 
influence of anemia on short-term mortality, defined as in-hospital mortality, in COVID-19 patients by a systematic review and meta-analysis of the available data.

\section{Materials and Methods}

\subsection{Data Sources and Searches}

The study was performed in accordance with the Preferred Report Items for Systematic Reviews and Meta-analyses (PRISMA) guidelines (Supplementary File S1) [13]. PubMed and Scopus databases were systematically searched for articles, published in English language, from inception through 1 September 2021, with the following Medical Subject Heading (MESH) terms: "COVID-19" OR "SARS-CoV-2" AND "Anemia". In addition, references from the included studies were screened to potentially identify other investigations meeting the inclusion criteria.

\subsection{Study Selection}

Specifically, inclusion criteria were: (i) studies enrolling subjects with a confirmed diagnosis of COVID-19; (ii) studies providing data on the prevalence of anemia among patients enrolled and (iii) adjusted odds ratios (aORs) estimating the short-term mortality risk among COVID-19 patients with anemia. Conversely, case reports, review articles, abstracts, editorials/letters, and case series with less than 10 participants were excluded. Each included article was independently evaluated by two reviewers (MZ, GR); in case of discrepancies a third author was involved (LF), and final consensus was achieved through discussion.

\subsection{Data Extraction and Quality Assessment}

Data were independently extracted by two reviewers (MZ, GR and LQ) using a standardized protocol. Disagreements, if any, were resolved by discussion. For this meta-analysis, the following data elements were extracted: sample size, mean age, number of non-survivors (NS), male gender, prevalence of anemia, major comorbidities such as HT, DM, cancer, heart failure (HF), coronary artery disease (CAD), chronic obstructive pulmonary disease (COPD) and chronic kidney disease (CKD) as well as the aOR for short-term mortality in COVID-19 patients with anemia. The quality of included studies was graded using the Newcastle-Ottawa quality assessment scale (NOS) [14].

\subsection{Outcomes}

The prevalence of anemia in COVID-19 patients was chosen as the primary outcome, while its associated mortality risk was selected as the secondary outcome.

\subsection{Data Synthesis and Analysis}

Continuous variables were expressed as median while categorical variables were expressed as counts and percentages. The cumulative prevalence of anemia $(n / \mathrm{N})$, defined as the ratio between patients with anemia $(n)$ and the number of patients enrolled in each study $(\mathrm{N})$, were pooled using a random effects model and presented with the corresponding $95 \%$ confidence interval (CI). Moreover, to estimate the mortality risk, data were pooled using the Mantel-Haenszel random effects model with odds ratio (OR) as the effect measure with $95 \%$ CI. Heterogeneity among studies was assessed using the Higgins and Thomson $\mathrm{I}^{2}$ statistic [15]. The presence of potential publication bias was verified by visual inspection of the funnel plot. Due to the low number of the included studies $(<10)$, small-study bias was not examined as our analysis was underpowered to detect such bias. A predefined sensitivity analysis (leave-one-out analysis) was performed removing 1 study at the time, to evaluate the stability of our results regarding the mortality risk. To further appraise the impact of potential baseline confounders in the estimation of the polled prevalence of anemia, a meta-regression analysis using age, gender, HT, DM and CKD as moderator variables was performed. All meta-analyses were conducted using Comprehensive MetaAnalysis software, version 3 (Biostat, Dallas, TX, USA). 


\section{Results}

\subsection{Search Results}

A total of 2527 articles were obtained by our search strategy. After excluding duplicates and preliminary screening, 1243 full-text articles were assessed for eligibility and 984 studies were excluded for not meeting the inclusion criteria while 254 for unavailable outcome, leaving 5 investigations fulfilling the inclusion criteria [6,7,16-18]. A flow diagram of the literature search and related screening process is shown in Figure 1.
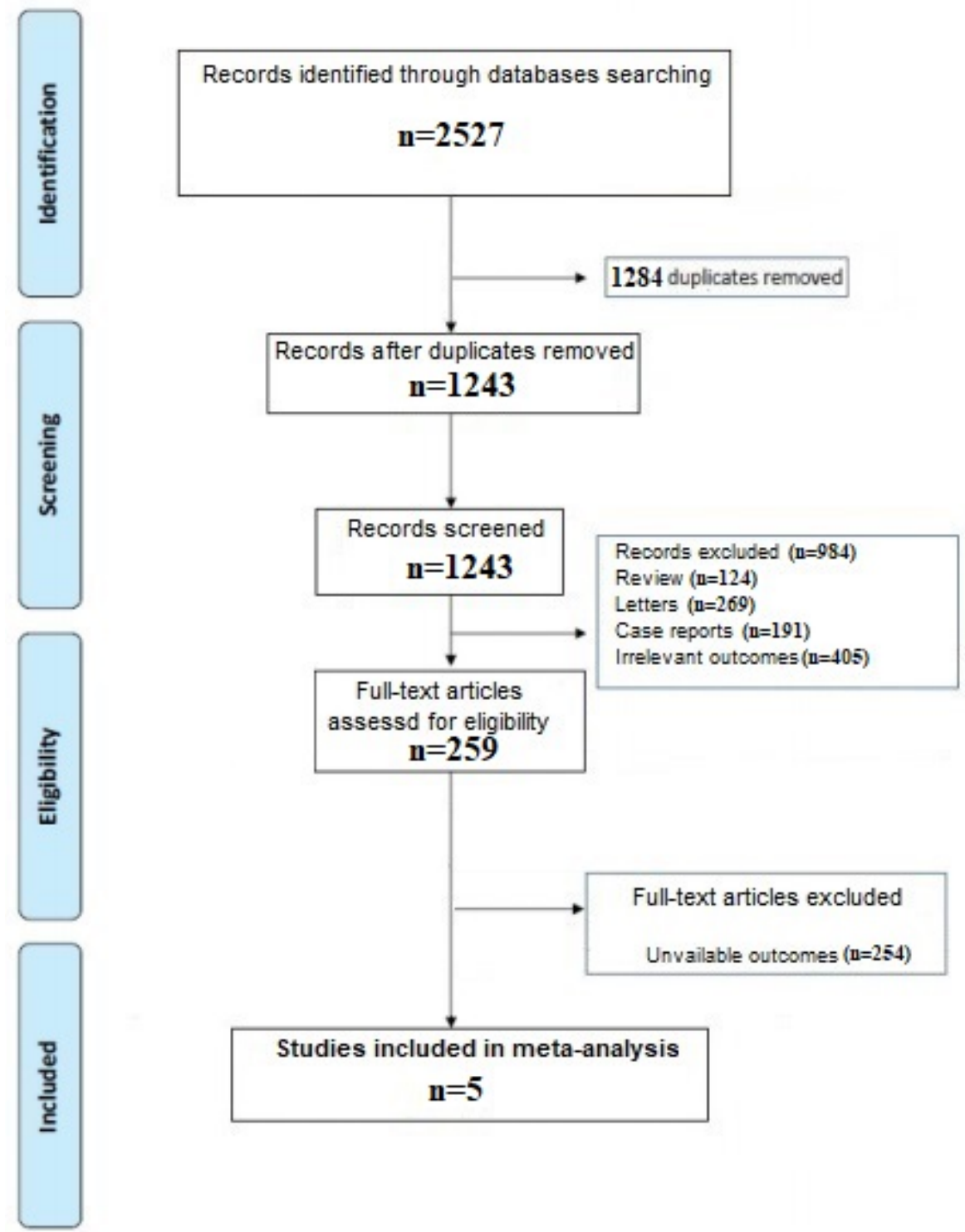

Figure 1. PRISMA flow diagram.

\subsection{Study Characteristics}

Overall, 9623 COVID-19 patients [3707 males (38.5\%)] were included in the analysis. The general characteristics of the included studies are summarized in Table 1. Despite that concomitant comorbidities were not systematically investigated by the analyzed studies, HT, DM and CKD were the most frequently observed $[n=1526 / 2692(56.6 \%), n=861 / 2629$ $(31.9 \%)$ and $n=824 / 2692(30.6 \%)]$, respectively. Quality assessment showed that all the studies were of moderate-high quality according to the NOS scale. 
Table 1. General characteristics of the population enrolled. IQR: Interquartile range; R: Retrospective study; P: Prospective study; S: Single center study; Multi: Multicenter study; NS: Non survivors; HT: Arterial Hypertension; HF: Heart failure; CAD: Coronary artery disease; COPD: Chronic obstructive pulmonary disease; CKD: Chronic kidney disease; $\mathrm{Hb}$ : Haemoglobin; NOS: Newcastle-Ottawa quality assessment scale; NR: Not reported.

\begin{tabular}{|c|c|c|c|c|c|c|c|c|c|c|c|c|c|c|c|}
\hline Author & Type & $\begin{array}{c}\mathbf{N}^{\circ} \text { of } \\
\text { pts }\end{array}$ & $\begin{array}{c}\text { Mean Age, Years } \\
\text { [IQR] }\end{array}$ & $\begin{array}{l}\text { Males, N } \\
(\%)\end{array}$ & $\begin{array}{c}\text { Anemia } \\
\text { Patients } \\
(\%)\end{array}$ & $\begin{array}{l}\text { NS, } n \\
(\%)\end{array}$ & $\begin{array}{l}\text { HT, } \\
\text { N (\%) }\end{array}$ & $\begin{array}{l}\text { DM, } \\
\text { N (\%) }\end{array}$ & $\begin{array}{l}\text { Cancer, } \\
\text { N (\%) }\end{array}$ & $\begin{array}{l}\mathrm{HF}, \mathrm{N} \\
(\%)\end{array}$ & $\begin{array}{l}\mathrm{CAD}, \\
\mathrm{N}(\%)\end{array}$ & $\begin{array}{l}\text { COPD, } \\
\text { N (\%) }\end{array}$ & $\begin{array}{l}\text { CKD, } \\
\text { N (\%) }\end{array}$ & $\begin{array}{l}\text { Anemia Cut-Off } \\
\text { (Hb g/dL) }\end{array}$ & NOS \\
\hline Al-Jarallah, et al. [16] & $\begin{array}{c}\mathrm{R} \\
\text { Multi } \\
\end{array}$ & 6931 & $44.1 \pm 17.2$ & $\begin{array}{c}2221 \\
(66.1) \\
\end{array}$ & $\begin{array}{l}554 \\
(7.9) \\
\end{array}$ & $176(2.5)$ & NR & NR & NR & NR & NR & NR & NR & $\mathrm{Hb} 10 \mathrm{~g} / \mathrm{dL}$ & 6 \\
\hline Oh, et al. [7] & $\begin{array}{c}\mathrm{R} \\
\text { Single }\end{array}$ & 733 & $65.0 \pm 16.0$ & $\begin{array}{l}372 \\
(50.8)\end{array}$ & $\begin{array}{l}438 \\
(59.8)\end{array}$ & $\begin{array}{c}219 \\
(29.9)\end{array}$ & $\begin{array}{c}559 \\
(76.3)\end{array}$ & $\begin{array}{c}357 \\
(48.7)\end{array}$ & $\begin{array}{c}145 \\
(19.8)\end{array}$ & $\begin{array}{c}117 \\
(16.0)\end{array}$ & NR & $\begin{array}{c}88 \\
(12.0)\end{array}$ & $\begin{array}{c}271 \\
(37.0)\end{array}$ & $\begin{array}{l}\mathrm{Hb} 12 \text { for } \\
\mathrm{Hb} 13 \text { for } \sigma^{7}\end{array}$ & 8 \\
\hline Dinevari, et al. [17] & $\begin{array}{c}\mathrm{P} \\
\text { Single }\end{array}$ & 1274 & $64.3 \pm 17.1$ & $\begin{array}{c}706 \\
(55.4) \\
\end{array}$ & $\begin{array}{c}615 \\
(48.2) \\
\end{array}$ & $\begin{array}{c}481 \\
(37.7)\end{array}$ & $\begin{array}{c}504 \\
(39.5) \\
\end{array}$ & $\begin{array}{c}288 \\
(22.6)\end{array}$ & $\begin{array}{c}56 \\
(4.6) \\
\end{array}$ & NR & NR & NR & $\begin{array}{c}112 \\
(8.7) \\
\end{array}$ & $\begin{array}{l}\mathrm{Hb} 12 \text { for } q \\
\mathrm{Hb} 13 \text { for } \sigma^{7}\end{array}$ & 7 \\
\hline $\begin{array}{l}\text { Bellmann-Weiler, } \\
\text { et al. [18] }\end{array}$ & $\begin{array}{c}\mathrm{R} \\
\text { Multi } \\
\end{array}$ & 259 & $\begin{array}{c}68 \\
(53-80) \\
\end{array}$ & 157 & $\begin{array}{c}64 \\
(24.7) \\
\end{array}$ & $\begin{array}{c}32 \\
(12.3)\end{array}$ & $\begin{array}{c}124 \\
(47.8) \\
\end{array}$ & $\begin{array}{c}45 \\
(17.3)\end{array}$ & $\begin{array}{c}21 \\
(8.1) \\
\end{array}$ & $\begin{array}{c}9 \\
(3.4) \\
\end{array}$ & $\begin{array}{c}35 \\
(13.5) \\
\end{array}$ & $\begin{array}{c}23 \\
(8.8) \\
\end{array}$ & $\begin{array}{c}15 \\
(5.7) \\
\end{array}$ & $\begin{array}{l}\mathrm{Hb} 12 \text { for } q \\
\mathrm{Hb} 13 \text { for } \sigma^{*}\end{array}$ & 8 \\
\hline Pilgram, et al. [6] & $\begin{array}{c}\mathrm{R} \\
\text { Multi }\end{array}$ & 426 & NR & $\begin{array}{c}251 \\
(58.9)\end{array}$ & $\begin{array}{c}46 \\
(38.0)\end{array}$ & $\begin{array}{c}12 \\
(2.8)\end{array}$ & $\begin{array}{c}339 \\
(80.7)\end{array}$ & $\begin{array}{c}171 \\
(41.1)\end{array}$ & $\begin{array}{c}85 \\
(20.7)\end{array}$ & $\begin{array}{c}132 \\
(33.1)\end{array}$ & $\begin{array}{l}133 \\
(33.5)\end{array}$ & $\begin{array}{c}53 \\
(12.7)\end{array}$ & $\begin{array}{c}426 \\
(100)\end{array}$ & $\mathrm{Hb} 10 \mathrm{~g} / \mathrm{dL}$ & 7 \\
\hline
\end{tabular}

\subsection{Pooled Prevalence of Anemia in COVID-19 Patients}

For the primary outcome of the study, the prevalence of anemia among COVID-19 patients ranged between $8.0 \%$ and 59.8\% [6,7,16-18]. A random effect model revealed a pooled prevalence of anemia in $25.6 \%$ of cases (95\% CI: $8.3-56.5 \%$ ). A high heterogeneity was observed in the analysis $\left(\mathrm{I}^{2}=99.7 \%\right.$ ) (Figure 2$)$. The relative funnel plot is presented in Supplementary File S2, Panel A.

Study name

\begin{tabular}{|c|c|c|c|c|c|}
\hline & $\begin{array}{l}\text { Event } \\
\text { rate }\end{array}$ & $\begin{array}{c}\text { Lower } \\
\text { limit }\end{array}$ & $\begin{array}{l}\text { Upper } \\
\text { limit }\end{array}$ & Z-Value & p-Value \\
\hline Al-Jarallah & 0,080 & 0,074 & 0,087 & $-55,162$ & 0,000 \\
\hline Oh & 0,598 & 0,562 & 0,632 & 5,248 & 0,000 \\
\hline Dinevari & 0,483 & 0,455 & 0,510 & $-1,232$ & 0,218 \\
\hline Bellmann-Weiler & 0,247 & 0,198 & 0,303 & $-7,734$ & 0,000 \\
\hline Pilgram & 0,108 & 0,082 & 0,141 & $-13,526$ & 0,000 \\
\hline $\begin{array}{l}\text { Random effect: } \\
\text { Tau-squared:2.2 } \\
\text { Q-value: } 1677.1 \\
\text { I-squared: } 99.70\end{array}$ & $\begin{array}{l}0,256 \\
28 \\
1 \\
0,0<0\end{array}$ & 0,083 & 0,565 & $-1,573$ & 0,116 \\
\hline
\end{tabular}

\section{Event rate and $95 \% \mathrm{Cl}$}

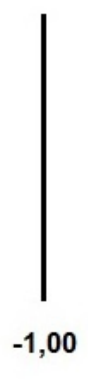

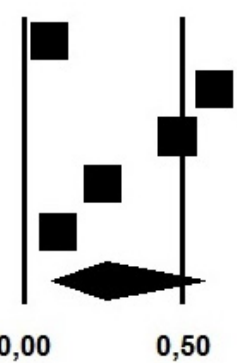

$-0,50$

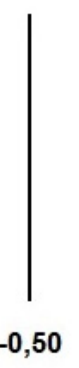

0,00

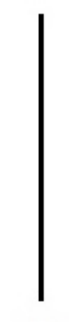

1,00

Figure 2. Pooled prevalence of anemia in COVID-19 patients.

\subsection{Meta-Regression}

Meta-regression analysis revealed a direct relationship between the prevalence of anemia and COVID-19 infection using age (Coeff. 0.091, 95\% CI: 0.024 to $0.159, p=0.007$ ) and CKD (Coeff. $0.082,95 \%$ CI: 0.019 to $0.131, p=0.004$ ) as moderating variables. Conversely, an inverse relationship was observed with male gender (Coeff. $-0.189,95 \% \mathrm{CI}:-0.230$ to $-0.140, p<0.0001)$. No associations were observed using HT $(p=0.68)$ and DM $(p=0.85)$ as moderators.

\subsection{Anemia and Mortality Risk in COVID-19 Patients}

Regarding the secondary outcome, four studies reported an aOR for the mortality risk in COVID-19 patients with anemia ( $n=2692$ patients, 1468 males) $[7,8,17,18]$. The variables used by each study to determine the aOR for the short-term mortality risk are presented in Table 2. On pooled analysis, patients with anemia showed a significant higher mortality risk in the short-term period (OR: 1.69, 95\% CI: 1.28-2.24, $p<0.001, \mathrm{I}^{2}=0 \%$ ) (Figure 3). The visual inspection of the relative funnel plot did not reveal significant evidence of publication bias (Supplementary File S2, Panel B). 
Table 2. Adjustment variables used to determine the adjusted OR for anemia and the risk of mortality. Oxygen saturation in arterial blood; LDH: Lactate dehydrogenase; CRP: C-reactive protein; CVD: Cardiovascular disease; eGFR: estimated glomerular filtration rate; PCT: Procalcitonin, HLD: Hyperlipidaemia; CKD: Chronic kidney disease.

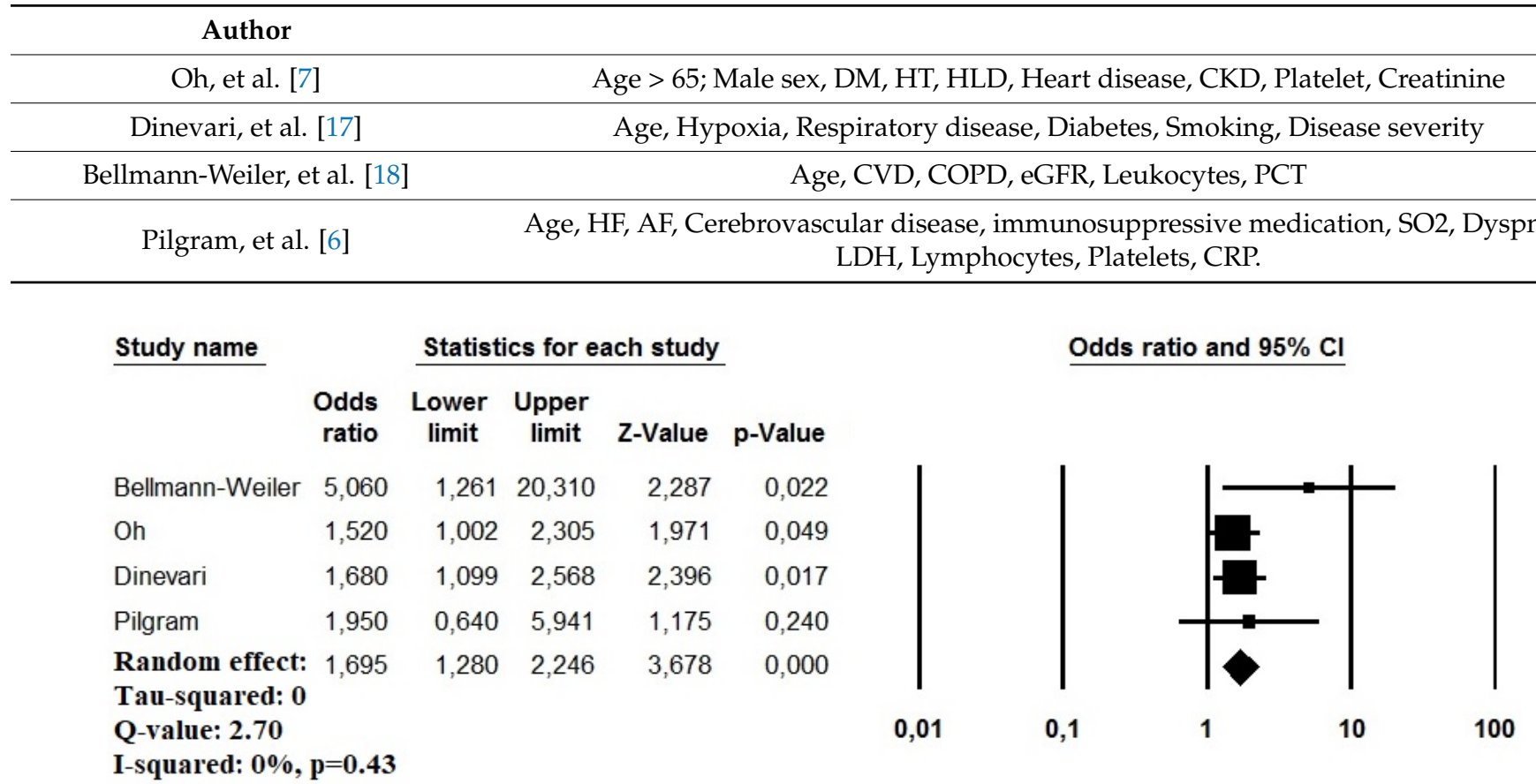

Figure 3. Forest plot investigating the mortality risk due to anemia in COVID-19 patients using a random-effect model.

\subsection{Sensitivity Analysis}

To evaluate the robustness of the results association, we performed a leave-one-out sensitivity analysis by iteratively removing one study at a time and recalculating the summary OR. The summary ORs remained stable (ranging between OR: 1.88, 95\% CI: 1.52-2.18, $p<0.001$ and OR: $1.34,95 \%$ CI: $1.12-1.46, p<0.001)$, indicating that our results were not driven by any single study.

\section{Discussion}

The present analysis demonstrates that anemia represents a relative common comorbidity in COVID-19 patients, being present in about one out of four infected patients. This association, which seems to be more frequent in women, was directly influenced by aging and concomitant presence of CKD. More importantly, SARS-CoV-2 infected patients with anemia had an approximately $70 \%$ higher risk of death in the short-term period compared to those without. Our findings are in accordance with the results presented by Al-Jarallah et al. who reported that COVID-19 patients having a hemoglobin $>10 \mathrm{~g} / \mathrm{dL}$ had lower odds of dying than those who were considered anemic (i.e., $\mathrm{Hb}<10 \mathrm{~g} / \mathrm{dL}$ ) (aOR: 0.33, 95\% CI: 0.20 to $0.55, p<0.001$ ) [16]. However, considering that these authors used in their multivariate analysis those patients without anemia as a reference group, we excluded this investigation from global risk estimation in our meta-analysis.

The high heterogeneity observed in the pooled prevalence analysis performed in our study is probably multifactorial. Indeed, both the limited number of studies satisfying the inclusion criteria as well as the relative few numbers of patients enrolled represent, per se, a potential source of heterogeneity. Besides, inherited biases derived from the original investigations may have further contributed to the heterogeneity level observed. In fact, different levels of methodological quality, sampling methods and definitions of anemia may have produced significant differences among studies. However, some part of the observed heterogeneity between studies could be explained by the results of the meta-regression. To this regard, it has been already reported that rates of anemia in men 
increased monotonically with age, while that of women increased bimodally with peaks in age groups 40-49 years and 80-85 years [19]. Furthermore, older COVID-19 patients have a higher risk of mortality, but in this case, women with anemia seem to have a worse outcome compared to males who generally have been reported to be at higher risk of death [20]. This difference can be explained by considering that some research has shown that the risk for CKD is slightly greater in women than in men [21] and that prominent gender disparities in CKD prevalence do exist among different countries [22]. However, the absence of heterogeneity in the estimation of mortality risk in COVID-19 patients with anemia as well as the results of the sensitivity analysis confirmed the robustness of our results.

From a pathophysiological perspective, $\mathrm{Hb}$ concentration represents one of the most important markers of oxygen-carrying capacity in the bloodstream. Therefore, anemia can further reduce oxygen delivery to peripheral tissue in COVID-19 patients who have an increased oxygen demand due the interstitial pneumonia $[7,23,24]$. Unfortunately, we cannot assess the potential prognostic impact of different types of anemia and relative pathophysiological pathways, such as deficient, excessive peripheral destruction, hereditary or blood loss. To this regard, adequate studies are needed to elucidate this issue. Probably, a major contributing role could have been played by the impairment of iron metabolism due to the underlying infection, resulting in the reduced availability of the metal for erythropoiesis and the production of $\mathrm{Hb}$ [8]. Our findings may have important implications in daily clinical practice: the prompt identification of patients with anemia remains critical to identify vulnerable populations who would require prioritization in treatment and close monitoring if infected, also in out-of-hospital settings.

\section{Limitations}

Our study has several limitations related to both the design of the reviews studied with all inherited biases and the relatively few investigations conducted on the issue. Indeed, only a few studies have analyzed the relationship between anemia and mortality risk, limiting our results and conclusions. Moreover, the relatively high heterogeneity observed in the estimation of the pooled prevalence of anemia in SARS-CoV-2 patients, which probably depends on the inclusion criteria as well as the design of the studies and different anemia criteria, may have led to infirm conclusions. However, the sensitivity analysis performed partially mitigates these limitations, confirming the validity of our results. Doubtless, anemia is not itself a disease but generally the manifestation of other underlying pathological conditions, often influenced by different concomitant comorbidities and/or risk factors. Unfortunately, we were not able to assess the causes of anemia in the analysis since none of the revised manuscripts provided such information. Further larger clinical studies are needed to confirm our preliminary results, also comparing the prognostic impact of different types of anemia in COVID-19 patients.

\section{Conclusions}

Anemia is present in about $25 \%$ of patients with COVID-19 infection and is associated with an increased risk of short-term mortality. The present results further reinforce the concept that concomitant comorbidities remain important predictors of COVID-19 patient outcome.

Supplementary Materials: The following are available online at https:/ / www.mdpi.com/article/10 .3390/idr13040085/s1. Supplementary File S1. PRISMA Checklist. Supplementary File S2. Funnel plots for (A) the pooled prevalence of anemia in COVID-19 patients and (B) for the mortality risk due to anemia in COVID-19 patients.

Author Contributions: Conceptualization: M.Z., G.R.; methodology: M.Z., G.R.; Validation: L.F.; formal analysis: M.Z., G.R.; data curation: G.R. and L.Q.; writing-original draft preparation: M.Z., G.R.; writing-review and editing: L.R. and G.Z.; supervision: L.R. All authors have read and agreed to the published version of the manuscript. 
Funding: This research received no external funding.

Institutional Review Board Statement: Not applicable.

Informed Consent Statement: Not applicable.

Data Availability Statement: All the data pertaining to the study are available in the manuscript.

Conflicts of Interest: The authors declare no conflict of interest.

\section{References}

1. De Giorgi, A.; Fabbian, F.; Greco, S.; Di Simone, E.; De Giorgio, R.; Passaro, A.; Zuliani, G.; Manfredini, R.; The Outcome and Comorbidity Evaluation of Internal Medicine COVID19 (Outcome-Intmed-COV19) Study Collaborators. Prediction of in-hospital mortality of patients with SARS-CoV-2 infection by comorbidity indexes: An Italian internal medicine single center study. Eur. Rev. Med. Pharmacol. Sci. 2020, 24, 10258-10266. [CrossRef] [PubMed]

2. Zuin, M.; Rigatelli, G.; Zuliani, G.; Rigatelli, A.; Mazza, A.; Roncon, L. Arterial hypertension and risk of death in patients with COVID-19 infection: Systematic review and meta-analysis. J. Infect. 2020, 81, e84-e86. [CrossRef] [PubMed]

3. Roncon, L.; Zuin, M.; Rigatelli, G.; Zuliani, G. Diabetic patients with COVID-19 infection are at higher risk of ICU admission and poor short-term outcome. J. Clin. Virol. 2020, 127, 104354. [CrossRef] [PubMed]

4. Bae, S.; Kim, S.R.; Kim, M.-N.; Shim, W.J.; Park, S.-M. Impact of cardiovascular disease and risk factors on fatal outcomes in patients with COVID-19 according to age: A systematic review and meta-analysis. Heart 2021, 107, 373-380. [CrossRef] [PubMed]

5. Zuin, M.; Rigatelli, G.; Bilato, C.; Cervellati, C.; Zuliani, G.; Roncon, L. Dyslipidaemia and mortality in COVID-19 patients: A meta-analysis. Qjm Int. J. Med. 2021. [CrossRef]

6. $\quad$ Pilgram, L.; The LEOSS Study Group; Eberwein, L.; Wille, K.; Koehler, F.C.; Stecher, M.; Rieg, S.; Kielstein, J.T.; Jakob, C.E.M.; Rüthrich, M.; et al. Clinical course and predictive risk factors for fatal outcome of SARS-CoV-2 infection in patients with chronic kidney disease. Infection 2021, 49, 725-737. [CrossRef] [PubMed]

7. Oh, S.M.; Skendelas, J.P.; Macdonald, E.; Bergamini, M.; Goel, S.; Choi, J.; Segal, K.R.; Vivek, K.; Nair, S.; Leff, J. On-admission anemia predicts mortality in COVID-19 patients: A single center, retrospective cohort study. Am. J. Emerg. Med. 2021, 48, 140-147. [CrossRef] [PubMed]

8. Tao, Z.; Xu, J.; Chen, W.; Yang, Z.; Xu, X.; Liu, L.; Chen, R.; Xie, J.; Liu, M.; Wu, J.; et al. Anemia is associated with severe illness in COVID-19: A retrospective cohort study. J. Med. Virol. 2020, 93, 1478-1488. [CrossRef] [PubMed]

9. Young, B.E.; Ong, S.W.X.; Kalimuddin, S.; Low, J.G.; Tan, S.Y.; Loh, J.; Ng, O.T.; Marimuthu, K.; Ang, L.W.; Mak, T.M.; et al. Epidemiologic Features and Clinical Course of Patients Infected with SARS-CoV-2 in Singapore. JAMA 2020, 323, 1488-1494. [CrossRef] [PubMed]

10. Groenveld, H.F.; Januzzi, J.L.; Damman, K.; van Wijngaarden, J.; Hillege, H.L.; van Veldhuisen, D.J.; van der Meer, P. Anemia and Mortality in Heart Failure Patients: A Systematic Review and Meta-Analysis. J. Am. Coll. Cardiol. 2008, 52, 818-827. [CrossRef] [PubMed]

11. Reade, M.C.; Weissfeld, L.; Angus, D.C.; Kellum, J.A.; Milbrandt, E.B. The prevalence of anemia and its association with 90-day mortality in hospitalized community-acquired pneumonia. BMC Pulm. Med. 2010, 10, 15. [CrossRef] [PubMed]

12. Vlagopoulos, P.T.; Tighiouart, H.; Weiner, D.E.; Griffith, J.; Pettitt, D.; Salem, D.N.; Levey, A.S.; Sarnak, M.J. Anemia as a Risk Factor for Cardiovascular Disease and All-Cause Mortality in Diabetes: The Impact of Chronic Kidney Disease. J. Am. Soc. Nephrol. 2005, 16, 3403-3410. [CrossRef] [PubMed]

13. Moher, D.; Liberati, A.; Tetzlaff, J.; Altman, D.G.; PRISMA Group. Preferred reporting items for systematic reviews and meta-analyses: The PRISMA statement. PLoS Med. 2009, 6, e1000097. [CrossRef] [PubMed]

14. Wells, G.A.; Shea, B.; O'Connell, D.; Peterson, J.; Welch, V.; Losos, M.; Tugwell, P. The Newcastle-Ottawa Scale (NOS) for Assessing the Quality if Nonrandomized Studies in Meta-Analyses. 2012. Available online: http://wwwohrica/programs/ clinical_epidemiology/oxfordasp (accessed on 2 September 2021).

15. Higgins, J.P.T.; Thompson, S.G.; Deeks, J.J.; Altman, D.G. Measuring inconsistency in meta-analyses. BMJ 2003, 327, 557-560. [CrossRef]

16. Al-Jarallah, M.; Rajan, R.; Al Saber, A.; Pan, J.; Al-Sultan, A.T.; Abdelnaby, H.; Alroomi, M.; Dashti, R.; Aboelhassan, W.; Almutairi, F.; et al. In-hospital mortality in SARS-CoV-2 stratified by hemoglobin levels: A retrospective study. eJHaem 2021, 2, 335-339. [CrossRef] [PubMed]

17. Dinevari, M.F.; Somi, M.H.; Majd, E.S.; Farhangi, M.A.; Nikniaz, Z. Anemia predicts poor outcomes of COVID-19 in hospitalized patients: A prospective study in Iran. BMC Infect. Dis. 2021, 21, 1-7. [CrossRef]

18. Bellmann-Weiler, R.; Lanser, L.; Barket, R.; Rangger, L.; Schapfl, A.; Schaber, M.; Fritsche, G.; Wöll, E.; Weiss, G. Prevalence and Predictive Value of Anemia and Dysregulated Iron Homeostasis in Patients with COVID-19 Infection. J. Clin. Med. 2020, 9, 2429. [CrossRef] [PubMed]

19. Le, C.H.H. The Prevalence of Anemia and Moderate-Severe Anemia in the US Population (NHANES 2003-2012). PLoS ONE 2016, 11, e0166635. [CrossRef] [PubMed]

20. Nguyen, N.T.; Chinn, J.; De Ferrante, M.; Kirby, K.A.; Hohmann, S.F.; Amin, A. Male gender is a predictor of higher mortality in hospitalized adults with COVID-19. PLoS ONE 2021, 16, e0254066. [CrossRef] [PubMed] 
21. United States Renal Data System. 2016 USRDS Annual Data Report: Epidemiology of Kidney Disease in the United States; National Institutes of Health: Bethesda, MD, USA; National Institute of Diabetes and Digestive and Kidney Diseases: Bethesda, MD, USA, 2016.

22. Bikbov, B.; Perico, N.; Remuzzi, G.; On behalf of the GBD Genitourinary Diseases Expert Group. Disparities in Chronic Kidney Disease Prevalence among Males and Females in 195 Countries: Analysis of the Global Burden of Disease 2016 Study. Nephron 2018, 139, 313-318. [CrossRef] [PubMed]

23. Böning, D.; Kuebler, W.M.; Bloch, W. The oxygen dissociation curve of blood in COVID-19. Am. J. Physiol. Cell. Mol. Physiol. 2021, 321, L349-L357. [CrossRef] [PubMed]

24. Taneri, P.E.; Gómez-Ochoa, S.A.; Llanaj, E.; Raguindin, P.F.; Rojas, L.Z.; Roa-Díaz, Z.M.; Salvador, D., Jr.; Groothof, D.; Minder, B.; Kopp-Heim, D.; et al. Anemia and iron metabolism in COVID-19: A systematic review and meta-analysis. Eur. J. Epidemiol. 2020, 35, 763-773. [CrossRef] [PubMed] 